\title{
Feasibility of Detecting
} Byproducts of Chemical Weapons Manufacturing in Environmental Media: A Preliminary Evaluation

M.L. Davisson, J.G. Reynolds, C. Koester, S.C. Chinn, R.S. Maxwell, A.H. Love, and B.E. Viani

\section{March 2003}

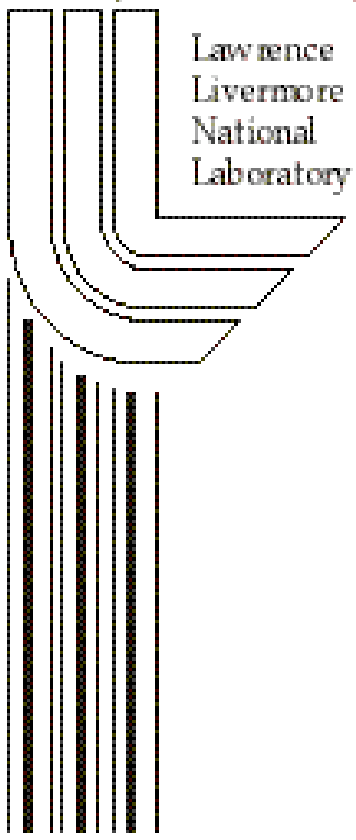




\section{DISCLAIMER}

This document was prepared as an account of work sponsored by an agency of the United States Government. Neither the United States Government nor the University of California nor any of their employees, makes any warranty, express or implied, or assumes any legal liability or responsibility for the accuracy, completeness, or usefulness of any information, apparatus, product, or process disclosed, or represents that its use would not infringe privately owned rights. Reference herein to any specific commercial product, process, or service by trade name, trademark, manufacturer, or otherwise, does not necessarily constitute or imply its endorsement, recommendation, or favoring by the United States Government or the University of California. The views and opinions of authors expressed herein do not necessarily state or reflect those of the United States Government or the University of California, and shall not be used for advertising or product endorsement purposes.

This work was performed under the auspices of the U. S. Department of Energy by the University of California, Lawrence Livermore National Laboratory under Contract No. W-7405-Eng-48.

This report has been reproduced directly from the best available copy.

Available electronically at http://www.doc.gov/bridge

Available for a processing fee to U.S. Department of Energy

And its contractors in paper from

U.S. Department of Energy

Office of Scientific and Technical Information

P.O. Box 62

Oak Ridge, TN 37831-0062

Telephone: (865) 576-8401

Facsimile: (865) 576-5728

E-mail: reports@adonis.osti.gov

Available for the sale to the public from

U.S. Department of Commerce

National Technical Information Service

5285 Port Royal Road

Springfield, VA 22161

Telephone: (800) 553-6847

Facsimile: (703) 605-6900

E-mail: orders@ntis.fedworld.gov

Online ordering: http:/ / www.ntis.gov/ordering.htm

\section{OR}

Lawrence Livermore National Laboratory

Technical Information Department's Digital Library

http:/ / www.llnl.gov/tid/Library.html 


\title{
Feasibility of Detecting Byproducts of Chemical Weapons Manufacturing in Environmental Media: A Preliminary Evaluation.
}

\author{
M.L. Davisson, J.G. Reynolds, C. Koester, S.C. Chinn, R.S. Maxwell, A.H. Love, B.E.
} Viani

\section{Background}

Quantitative information on the environmental transport and fate of organophosphorus nerve agents has been limited to studies conducted at high concentration representative of acute doses (Munroe et al. 1999). Nerve agents have relatively rapidly degradation rates at acute levels, and first order degradation pathways and half-lives have been characterized. However, similar knowledge is lacking in the open literature on the long-term environmental persistence of nerve agents, their manufacturing precursors and byproducts, and their degradation products, particularly at sub-acute or chronic health levels. Although many recent publications reflect low-level detection methods for chemical weapons signature compounds extracted from a variety of different media (e.g. D’Agostino et al., 2001; Kataoka et al., 2001), little of this work answers questions regarding their adsorptive character and chemical persistence. However, these questions are a central theme to both the detection of illegal chemical weapons manufacturing, as well as determining long-term cleanup needs and health risks associated with potential terrorist acts using such agents.

Adsorption onto environmental surfaces can enhance the persistence of organophosphorus compounds, particularly with strong chelators like phosphonic acids. In particular, organophosphorus compound adsorption can lead to irreversible binding (e.g. Aubin and Smith, 1992), and current methods of chemical extraction and solid-state detection are challenged to detect them. This may be particularly true if the adsorbed compound is of a low initial concentration because it may be that the most preferred adsorption sites form the strongest bonds. This is particularly true in mixed media having various adsorption domains that adsorb at different rates (e.g. Weber and Huang, 1996). For high enough initial concentrations, sorption sites become saturated and solvent extraction has a relatively high efficiency. It is no surprise that many $\mathrm{CW}$ fate studies can report findings using traditional extraction or solid-state methods of detection, since release concentration exceed the capacity of environmental media to adsorb or degrade them.

This report documents a test using solid-state ${ }^{31} \mathrm{P}-\mathrm{NMR}$ and GC/MS methods to delineate two adsorbed phosphonates on a uniform silica gel substrate at different concentrations. The test sought to determine the sensitivity of ${ }^{31} \mathrm{P}-\mathrm{NMR}$ detection, delineate adsorption character of the phosphonates, quantify their extraction efficiency using different solvents, and test the phosphonate mobility and photodegradability under short-term idealized conditions. The results show that solid-state detection at the experimental conditions can detect individual phosphonate species down to the $100 \mathrm{ppm}$ level. Sensitivity could be further increased using larger samples and longer collection times. Solvent extraction of the phosphonates from the silica gel showed that a chlorinated solvent (methylene chloride) produced poor recovery for phosphonic acids from the silica gel, whereas methanol used as a solvent achieved high extraction efficiency. The phosphonates used showed strong aqueous mobility in a silica gel column 
experiment, with a small but significant amount left adsorbed to the substrate. A 96 hour photo-degradation experiment showed no degradation of the compounds.

Methods

Samples of diisopropylmethylphosphonate (DIMP) and methyl phosphosphonic acid (MPA) were obtained in relatively high purity $(>97 \%)$ from Aldrich. Silica gel was obtained from Baxter Scientific having a pore size of $60 \AA$. The silica gel was prepared for the sorption experiments by heating for 2 hours at $120^{\circ} \mathrm{C}$ and cooled by vacuum dessication in order to drive off most surface-bound water. The silica gel surface area was not measured, however, it was anticipated to be in the hundreds of square meters per gram. Adsorbed concentrations of compounds used in the experiments were expected to be far below saturation of available adsorption sites.

All solutions of DIMP and MPA were prepared by dissolving in methylene chloride $\left(\mathrm{CH}_{2} \mathrm{Cl}_{2}\right)$. Stock solutions of DIMP and MPA were made in $\mathrm{mg} / \mathrm{ml}$ concentrations and diluted to the desired concentrations used for the sorption, mobility, and photo-degradation experiments. For ${ }^{31}$ P-NMR sensitivity experiments, MPA and DIMP solutions were slurried with silica gel for approximately 30 minutes. The slurry was then rotary-evaporated to dryness and split for subsequent extraction and chromatographic analysis and ${ }^{31} \mathrm{P}-\mathrm{NMR}$ analysis. In experiment \#1, diluted solutions were spiked on $2 \mathrm{~g}$ of silica gel to achieve $1000 \mathrm{ppm}$ adsorbed concentration. After rotary-evaporation, an aliquot of the spiked silica gel was diluted with an appropriate amount of unspiked silica gel to form $100 \mathrm{ppm}$ and $10 \mathrm{ppm}$ spiked substrates. In subsequent batch experiments, silica gel was spiked with prepared serial dilutions of DIMP and MPA.

The mobility experiment was carried out by packing $1 \mathrm{~g}$ of clean silica gel into a syringe barrel. Packed on top of this was $1 \mathrm{~g}$ of a $1000 \mathrm{ppm}$ spiked silica gel. The materials were separated by a glass frit. $80 \mathrm{~mL}$ of distilled water were dripped through the silica gel at 0.5 to $1 \mathrm{~mL} / \mathrm{min}$ and a vacuum applied to the bottom to simulate a nonsaturating rain event of about $15 \mathrm{~cm}$. The two silica gel aliquots were separately analyzed for DIMP and MPA.

The photodegradation experiment was conducted by exposing $5 \mathrm{~g}$ of $1000 \mathrm{ppm}$ spiked silica gel for a total of 96 hours in ambient sunlight conditions. This was performed in mid September in Livermore, California under cloudless days. The temperature ranged from 55 to $99^{\circ} \mathrm{F}$, the relative humidity from 20 to $95 \%$, and the solar radiation from zero to 600 watts per square meter.

Silica gel extraction for chromatographic analysis was accomplished by extracting the solid three consecutive times with $\mathrm{CH}_{2} \mathrm{Cl}_{2}$. All extracts were combined and diluted for direct injection for $\mathrm{GC} / \mathrm{MS}$ analysis. Later extractions were performed using $\mathrm{MeOH}$ in order to compare extraction efficiencies between the two solvents.

GC/MS analyses were performed directly on DIMP using splitless injection into a $30 \mathrm{~m} \times 0.25 \mathrm{~mm}$ id $\times 0.25 \mathrm{um}$ film thickness (J\&W Scientific) column and the following thermal program: temperature held at $35^{\circ} \mathrm{C}$ for $1 \mathrm{~min}$, ramp at $10^{\circ} \mathrm{C} / \mathrm{min}$ to $300^{\circ} \mathrm{C}$ (hold for $3 \mathrm{~min}$ ). Helium, with a linear velocity of $36 \mathrm{~cm} / \mathrm{sec}$, was used as carrier gas. The quadrupole mass spectrometry (Agilent Model 5973) was scanned from 29-500 u at a rate of $1.6 \mathrm{scans} / \mathrm{sec}$. Sample analysis for MPA was accomplished by evaporating sample 
extract to dryness, reconstituting in $200 \mathrm{uL}$ BSTFA derivatizing agent, and heating at $60^{\circ} \mathrm{C}$ for $30 \mathrm{~min}$, followed by direct injection into the GC/MS.

Solid state NMR spectra of MPA and DIMP were collected using a Bruker DRX$500 \mathrm{NMR}$ spectrometer with an operating ${ }^{1} \mathrm{H}$ frequency of $500.13 \mathrm{MHz}$ and ${ }^{31} \mathrm{P}$ frequency of $202.46 \mathrm{MHz}$. The samples were held under magic angle spinning conditions with speeds of $5 \mathrm{kHz} .{ }^{31} \mathrm{P}$ spectra were acquired by means of single pulse excitation with high power proton decoupling, using pulse widths of $6 \mathrm{~ms}$ and delay times of $5 \mathrm{sec}$. Acquisition times ranged from hours to days, depending on the sample concentration and desired signal to noise ratio. For experimental samples measuring extraction recovery, mobility, and photo-degradation, 15,000 scans were taken for a total acquisition time of 21 hours. With specific recovery experiments requiring careful mass balancing, exact NMR intensities were obtained by dividing the integrated signal intensities by the sample mass.

\section{Results and Discussion}

${ }^{31} \mathrm{P}-\mathrm{NMR}$ results from experiment \#1 are presented in Figures 1a-1c. The three separate spectra of MPA show different concentrations adsorbed to silica gel. The 100 and $10 \mathrm{ppm}$ samples were prepared by diluting the $1000 \mathrm{ppm}$ sample with unspiked silica gel. The 1000 ppm spectra shows the phosphorus-methyl (P-C) bond of MPA as a broad peak centered about a chemical shift of $22 \mathrm{ppm}$ with a weaker broad shoulder centered around $18 \mathrm{ppm}$. The $22 \mathrm{ppm}$ peak is likely mobile MPA, whereas, the $18 \mathrm{ppm}$ shoulder indicates restricted motion consistent with chemically adsorbed MPA. There is also a small peak centered around $0 \mathrm{ppm}$ corresponding to a phosphate group. The spectra of the 100 and 10 ppm samples show a very weak presence of the P-C bond regions, but a strong and sharp peak corresponding to phosphate. The phosphate peak increases intensity with decreasing MPA concentration. This result is consistent with a phosphate contamination in the silica gel, since increased dilution of the MPA with unspiked silica gel results in an increased phosphate. All subsequent spiking of silica gel used serial dilution of MPA and DIMP rather than dilution with unspiked silica gel.

${ }^{31}$ P-NMR spectra for samples prepared by serial dilution of MPA and DIMP in $\mathrm{CH}_{2} \mathrm{Cl}_{2}$ are shown in Figures 2 and 3 . The 1000 ppm and 100 ppm MPA spiked silica gel show a single peak with a chemical shift centered about $22 \mathrm{ppm}$, and note no $0 \mathrm{ppm}$ shift corresponding to phosphate can be observed. A three-day collection time for the $100 \mathrm{ppm}$ MPA appears to be sufficient for detection. The 1000 ppm DIMP spiked silica gel is easily detected with a one day scan and shows a sharp peak with a chemical shift at approximately $26 \mathrm{ppm}$ corresponding to $\mathrm{P}-\mathrm{C}$ bond of a mobile phase, and another broad peak centered around $20 \mathrm{ppm}$ indicating an adsorbed immobile phase. The $100 \mathrm{ppm}$ DIMP spiked silica gel shows a somewhat broad, low intensity peak at a chemical shift of $26 \mathrm{ppm}$, but the signal to noise is relatively low and additional peaks such as at $20 \mathrm{ppm}$ are not detected even at a three day scan.

In comparison to other studies, the ${ }^{31} \mathrm{P}-\mathrm{NMR}$ approach used in our study using the 100 ppm DIMP and MPA spiked silica gels are relatively sensitive. For example, a solidstate ${ }^{31}$ P-NMR study of VX degradation on concrete was conducted at 20,000 ppm and parent and hydrolysis products were measured directly in the sample cell (Wagner et al., 2001). Using cylindrical internal reflection FTIR methods, Barja et al. (1999) conducted MPA adsorption studies on goethite under variable adsorption densities. The lowest 
density measured in their study was $4300 \mathrm{ppm}$. The ${ }^{31} \mathrm{P}-\mathrm{NMR}$ data collected for our study shows that approximately a 10 fold lower sensitivity is achievable under the experimental conditions compared to these other studies. However, given the current NMR conditions, speciation of the intermolecular interaction is limited compared to FTIR approaches conducted at higher concentrations.

It has been recognized from several studies of phosphonate compound interaction with soil that they compete with orthophosphate sorption sites on minerals (McBride and Kung, 1989; de Jonge and de Jonge, 1999), or can have even stronger non-specific adsorptive interaction with soil organic matter (Piccolo et al., 1996). The main mechanisms of sorption appear either by direct cation binding to oxygen in the phosphonates (e.g Wagner et al., 1999), or by hydrogen bonding in cases of hydrated cation mineral surfaces with soil organics (e.g. McConnell and Hossner, 1989; Piccolo and Celano, 1994). Phosphonate adsorption and the P-C bond are strong and persistent for inorganic sorptive materials even at high temperatures (Mitchell et al., 1997). Furthermore, adsorbed phosphonates commonly exhibit multi-dentate structural interaction at low adsorption density over a relatively wide $\mathrm{pH}$ range, whereas high adsorption density appears to be dominated by mono-dentate interaction (Barja et al., 1999).

From the ${ }^{31} \mathrm{P}-\mathrm{NMR}$ results collected from our preliminary study, two adsorbed phases are distinguished from the DIMP spectrum at $1000 \mathrm{ppm}$ (Figure 2). The chemical shift centered around $20 \mathrm{ppm}$ defines a broad peak relatively to the one centered at 26 ppm. The broadness is characteristic of restricted vibrational and rotational motion, and its relatively high intensity suggest much of the DIMP forms bonds with silica gel that restrict motion. Definition of bonding structure is beyond this preliminary analysis, but may be due to hydrogen bonding between silica hydroxyl sites and the alkoxyl phosphonate groups, or silica directly bonded to phosphorus bonded oxygen by loss of $\mathrm{H}_{2} \mathrm{O}$. For MPA at $1000 \mathrm{ppm}$, a similar broad peak indicating restricted motion was not observed, but a small indication of such a form was seen in Figure 1a. Further work is needed to resolve this discrepancy.

Extraction recovery experiments of spiked MPA and DIMP on silica gel showed variable results. $\mathrm{CH}_{2} \mathrm{Cl}_{2}$ extraction of DIMP resulted in $<10 \%$ recovery by GC/MS analysis. The remaining DIMP was still bound to the silica gel as confirmed by ${ }^{31} \mathrm{P}-\mathrm{NMR}$ measurement of the extracted silica gel. Extraction of DIMP with $\mathrm{MeOH}$ was $102 \%$, and the extracted silica gel gave no DIMP-related NMR signal. MPA extraction efficiencies were $27 \%$ using $\mathrm{MeOH}$, as indicated by the GC/MS of the BSTFA derivative. ${ }^{31} \mathrm{P}-\mathrm{NMR}$ results on the extracted silica gel are not available at this time. Poor extraction recovery has been observed in studies that spiked soil at 10-1000 ppm concentrations with various nerve agent-related phosphonates and phosphonic acids (D’Agostino et al., 2001). $\mathrm{CH}_{2} \mathrm{Cl}_{2}$ extraction typically resulted in $<53 \%$ efficiency for phosphonic acid derivatives of nerve agents, and $22-93 \%$ recovery for phosphonates. Soman had poorest recovery. Water actually resulted in better extraction efficiency for phosphonic acids.

The mobility study showed that $80 \%$ of the DIMP spiked into the top silica gel layer was dissolved in the water collected at the bottom of the syringe barrel. Separate extractions of the spiked silica gel layer and unspiked one showed that approximately $10 \%$ of the DIMP was retained on the spiked layer and $10 \%$ was adsorbed to the bottom layer. These results indicate that the DIMP is mobile in a sandy soil condition, but even 
under idealized conditions in the experiment, significant quantities are retarded and adsorbed to the matrix.

The short photo-degradation study resulted in no loss of either the DIMP or MPA as confirmed by both GC/MS and ${ }^{31} \mathrm{P}-\mathrm{NMR}$.

\section{Conclusions}

Adsorption plays an important role in the retention and recalcitrance of CWrelated signatures. Under the idealized conditions of the spiked silica gel used in our experiments, results showed that recalcitrance resulted under simulated rain and shortterm photo-exposure conditions. This recalcitrance is likely due to adsorptive bonding between silica hydroxyl, or the silica itself, with the phosphorus bonded oxygen, similar to that commonly observed for orthophosphate in soils.

Detecting evidence of this recalcitrance was aided by both liquid extraction GC/MS methods and solid state NMR. Extraction efficiency was poor for commonly used solvents such as $\mathrm{CH}_{2} \mathrm{Cl}_{2}$, but that efficiency was vastly improved using $\mathrm{MeOH}$. With more complex substrates such as soils, extraction efficiency with either solvent is anticipated to be poorer. Solid-state ${ }^{31} \mathrm{P}-\mathrm{NMR}$ measurements easily detected adsorbed MPA and DIMP at the 100 ppm level, far below what has been illustrated in the literature thus far for similar studies.

\section{Next Steps}

Adsorptive behavior of organophosphorus compounds and structural relationships with a substrate can be better elucidated with a combined FTIR and NMR approach. Attenuated total reflectance FTIR methods possibly provide a sensitive approach for characterizing and quantifying adsorption chemistry, particularly in iron-rich materials that interfere with NMR detection due to the paramagnetism. In addition, current sensitivity of ${ }^{31} \mathrm{P}-\mathrm{NMR}$ techniques used for this preliminary study could be significantly improved by increasing sample size and increasing analysis times.

Extraction efficiency needs to be tested as function of initial spiked concentration. If adsorption character plays an important role in retention on a solid substrate, then extraction efficiency should decrease with decreased initial spiked concentration. This experiment can easily test for nerve agents and related products adsorbed to simple and uniform material such as silica gel.

Further mobility and associated hydrolysis studies are needed to better understand $\mathrm{CW}$ and related product behavior representative of typical dynamic field conditions.

Long-term exposure studies on more complex matrices using a white light source is warranted. In the case of mixed mineral and organic assemblages, when photo-induced catalysis is possible, light exposure may actually decrease recalcitrance.

\section{$\underline{\text { References }}$}

Aubin A.J. and Smith A.E., 1992, Extraction of [C-14] glyphosate from Saskatchewan soils. J. Agri. Food Chem., 40, 1163-1165.

de Jonge, H. and de Jonge, L.W., 1999, Influence of $\mathrm{pH}$ and solution composition on the sorption of glyphosate and prochloraz to a sandy loam soil. Chemosphere, 39, 753-763. 
D’Agostino, P.A., Hancock, J.R., Provost, L.R., 2001, Determination of sarin, soman, and their hydrolysis products in soil by packed capillary liquid chromatographyelectrospray mass spectrometry. J. Chromat. A, 912, 291-299.

Kataoka, M., Tsuge, K., Takesako, H., Hamazaki, T., Seto, Y., 2001, Effect of pedological charcateristics on aqueous soil extraction recovery and tertbutyldimethylsilylation yield for gas chromatography-mass spectrometry of nerve gas hydrolysis products from soils. Environ. Sci. Technol., 35, 1823-1829.

McBride, M. and Kung, K., 1989, Complexation of glyphosate and related ligands with iron (III). Soil Sci. Soc. Am. J., 53, 1668-1673.

McConnell, J..S. and Hossner, L.R., 1989, X-ray diffraction and infrared spectroscopic studies of absorbed glyphosate. J. Agric. Food Chem. 37, 555-560.

Mitchell, M.B., Sheinker, V.N., Mintz, E.A., 1997, Adsorption and decomposition of dimethyl methylphosphonate on metal oxides. J. Phys. Chem. B, 101, 11192-11203.

Munro, N.B., Talmage, S.S., Griffin, G.D., Waters, L.C., Watson, A.P., King, J.F., Hauschild, V., 1999, The sources, fate, and toxicity of chemical warfare agent degradation products. Environ. Health Perspect. 107, 933-974.

Piccolo, A. and Celano, G., 1994, Hydrogen-bonding interactions between the herbicide glyphosate and water-soluble humic substances. Environ. Toxicol. Chem., 13, 17371741.

Wagner, G.W., Bartram, P.W., Koper, O., Klabunde, K.J., 1999, Reactions of VX, GD, and HD with nanosize MgO. J. Phys. Chem. B, 103, 3225-3228.

Wagner, G.W., O'Connor, R.J., Procell, L.R., 2001, Preliminary study on the fate of VX in concrete. Langmuir, 17, 4336-4341.

Weber, W.J. and Huang, W., 1996, A distributed reactivity model for sorption by soils and sediments. 4. Intraparticle heterogeneity and phase distribution relationships under nonequilibrium conditions. Environ. Sci. Technol., 30, 881-888. 


\section{P MAS NMR Spectra of MPA on silica gel}
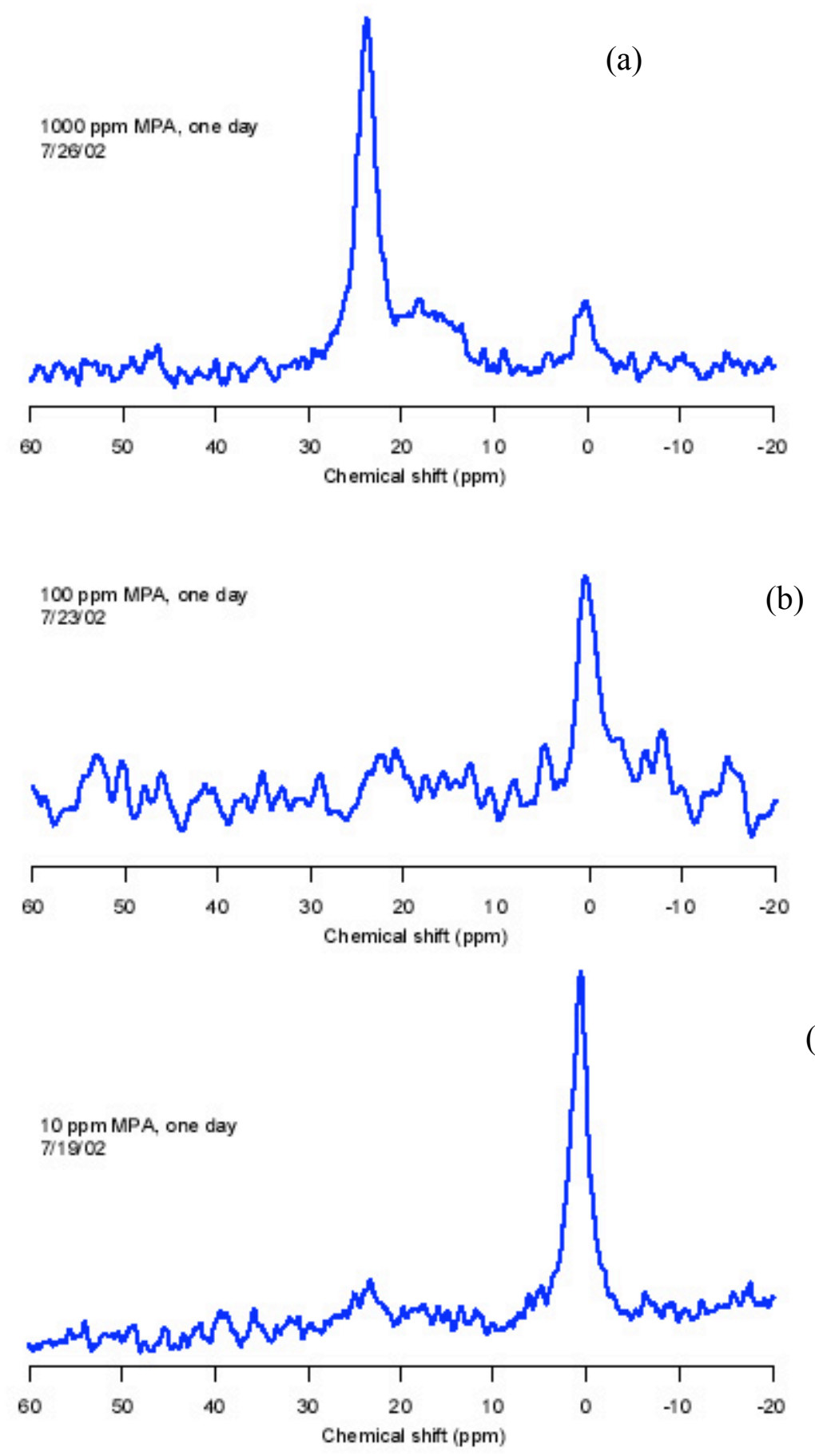

Figure 1 


\section{P MAS NMR Spectra, sample on silica gel}

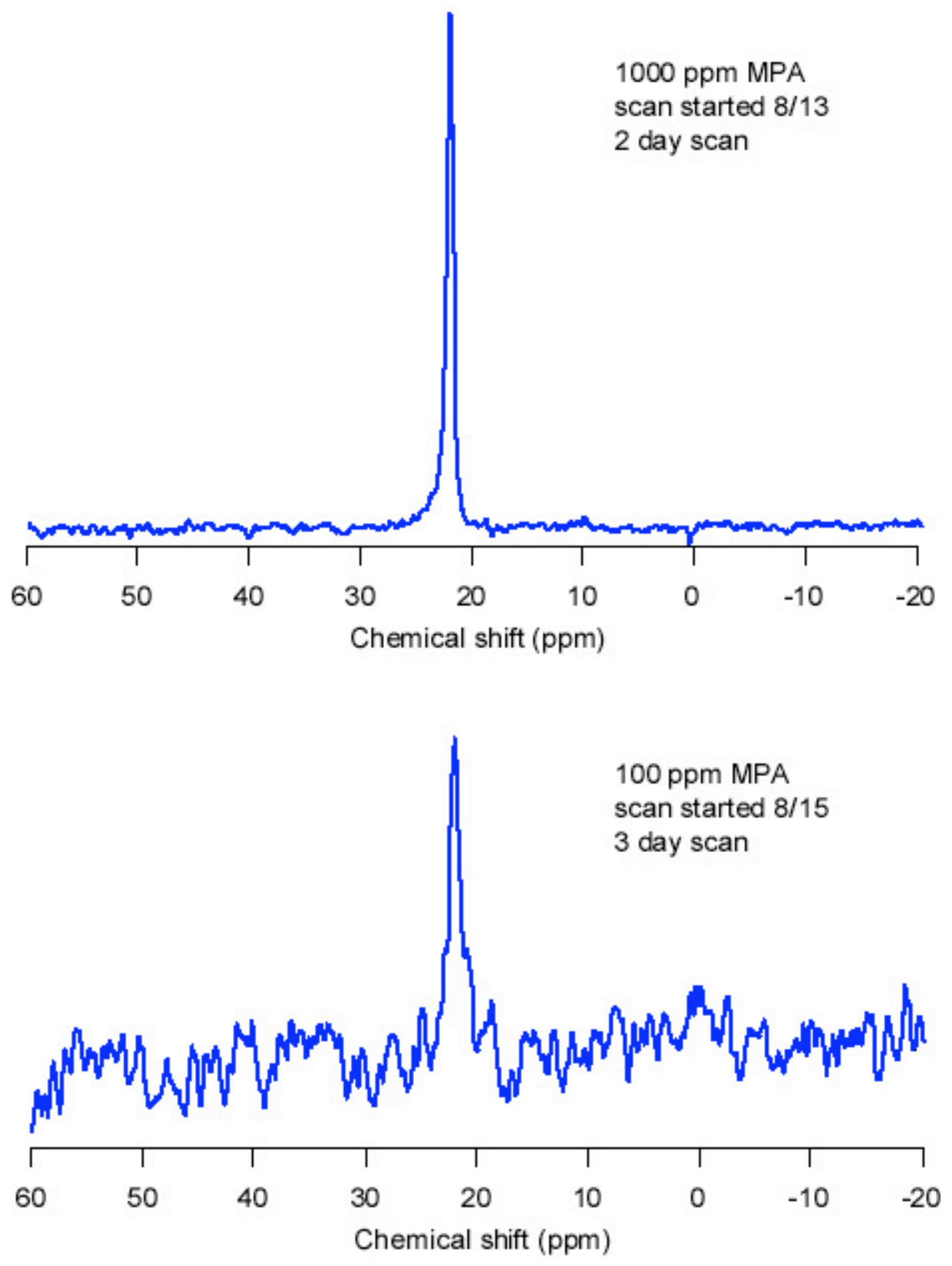

Figure 2 


\section{P MAS NMR Spectra, sample on silica gel}
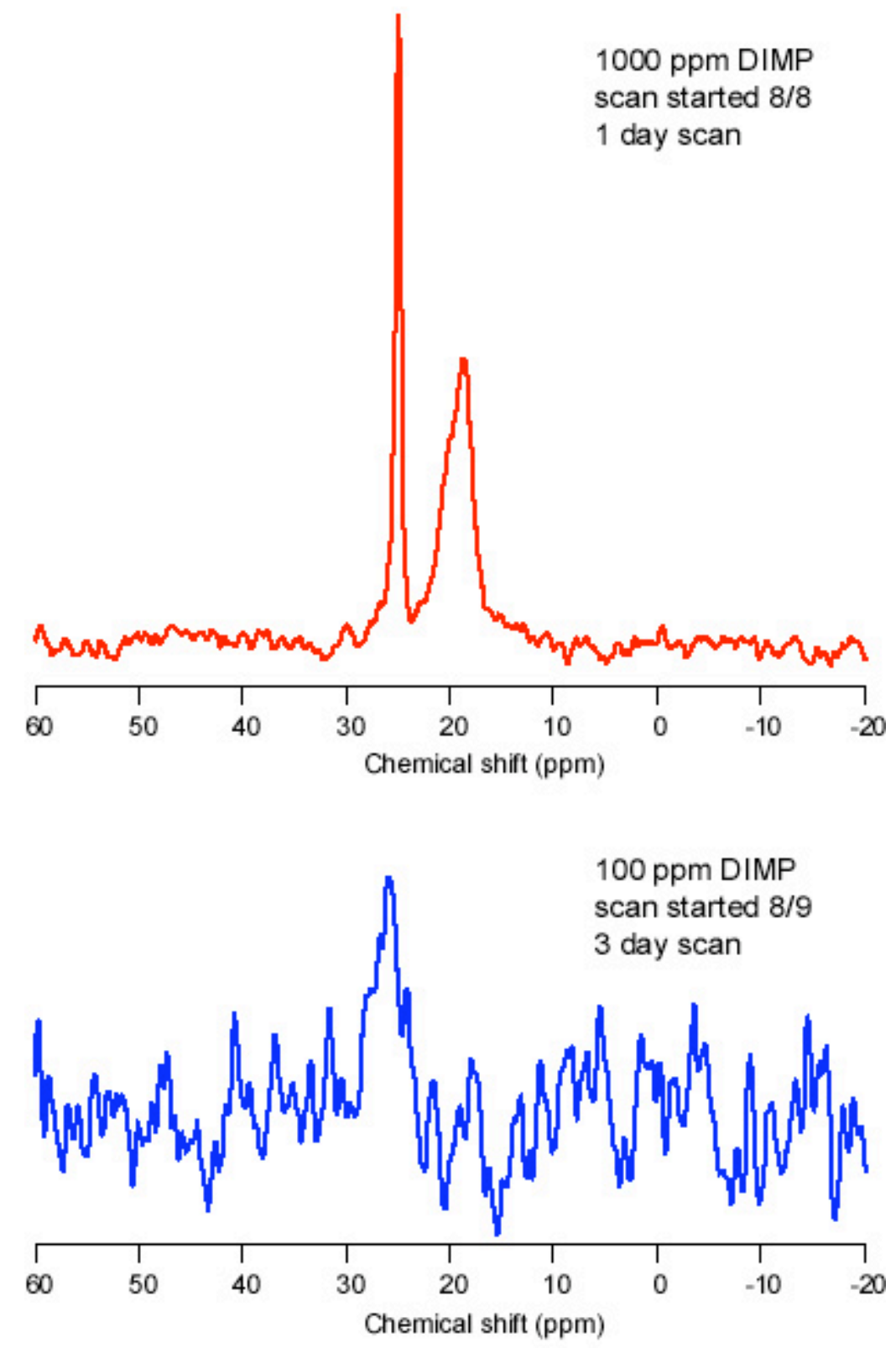

Figure 3 